\title{
The Use of Colorimeters to Support Remote Sensing Techniques on Asphalt Pavements
}

\author{
Christodoulos Mettas ${ }^{1,2, *}$ (]) Evagoras Evagorou 1,2, Athos Agapiou 1,2(1) \\ and Diofantos Hadjimitsis ${ }^{1,2}$ \\ 1 Department of Civil Engineering and Geomatics, Faculty of Engineering and Technology, Cyprus University \\ of Technology, 3036 Lemesos, Cyprus; evagoras.evagorou@cut.ac.cy (E.E.); athos.agapiou@cut.ac.cy (A.A.); \\ d.hadjimitsis@cut.ac.cy (D.H.) \\ 2 Eratosthenes Centre of Excellence, 3036 Lemesos, Cyprus \\ * Correspondence: christodoulos.mettas@cut.ac.cy; Tel.: +357-25-245052
}

Received: 29 August 2020; Accepted: 26 November 2020; Published: 28 November 2020

check for updates

\begin{abstract}
Characterization of asphalt pavements, based on ground spectroradiometers, has been studied in the past to determine their spectral response concerning the physical, chemical, and condition properties of the pavement. This paper suggests an alternative technique for characterizing ageing of asphalt pavements using a colorimeter. Colorimeters are considered as affordable equipment in laboratories in contrast to other scientific instruments and turn remote sensing ground techniques more accessible to industry. Therefore, the study proposes a new methodology indicating how colorimeters can be used in combination with satellite data for the age characterization of asphalt pavements. Spectroradiometer data are compared in a two-way methodology to colorimeter data. The final steps of the methodology used in the study show very similar results for both equipment after a comparison of separability indices (Euclidean and Mahalanobis distances). It is a fact that colorimeter data can be used as ground truth data. The application was performed using an in-band analysis of WorldView 3 (WV3) spectral bands situated in the visible electromagnetic spectrum. Based on the findings of this study, we proposed the Normalized Difference Equation/filter for asphalt Pavement Age characterization Index (NDPAI).
\end{abstract}

Keywords: colorimeter; spectroradiometer; asphalt pavements; remote sensing; WorldView 3; color to spectral; spectral to color

\section{Introduction}

Remote sensing techniques are used on asphalt pavements to study their physical and chemical characteristics, and also to evaluate the condition of pavements such as ageing and material composition [1-6]. There are various techniques in remote sensing that can be used for the study of asphalt concrete's behavior, including spectral libraries, Unmanned Aerial Vehicles (UAV's), digital sensors (such as RGB and thermal imaging), Ground Penetrating Radars (GPRs), and satellite data [7-11]. The most common equipment to be used for ground truth data is a spectroradiometer. Spectroradiometric ground data can be used to understand the spectral behavior (i.e., spectral signatures) of the asphalt pavements, as this is also obtained through satellites. There is a variety of spectroradiometers to be used depending on its use (i.e., the desired spectral wavelength), but reliable ones can be considered as expensive. In addition, such equipment is meant to be used only by experts.

In this study, an effort was made to reduce the cost of scientific laboratory equipment, make remote sensing research more understandable and accessible to the industry by introducing colorimeters for the characterization of asphalt pavements. The science of colorimetry demonstrates that the color of an object depends on the spectral composition of the incident light, the object's spectral reflectance 
or transmittance, the observer's spectral response, and the illuminating and viewing geometry [12]. One very common color space used in colorimeters is CIELAB, which refers to a lightness axis $\mathrm{L}^{*}$, a redness (positive)_-greenness (negative) axis $\mathrm{a}^{*}$, and a yellowness (positive)—blueness (negative) axis $b^{*}$. L*a*b* is a uniform color space (UCS), i.e., the threshold is represented by equal distances in a color space [12,13].

As far as asphalt pavements are concerned, it is imperative to understand their color and degradation phases since this knowledge leads to safer roads and reduces the overall cost for maintenance. Colored pavements are used for safety improvements and also to calm traffic, understand different urban spaces, and identify dedicated or preferential routes (e.g., bus lanes, bicycle lanes, etc.) [14-16]. Furthermore, asphalt is considered as an energy storage element [17]. Otherwise stated, it behaves as an elastic solid, able to recover small deformations, during winter, while in the summertime, it behaves as a viscous material when the traffic load is applied to it [18]. The energy absorbed by the asphalt pavements decreases with time. This results in the reduction of the heat island effect, the increase in air quality, and savings in the reductions of air-conditioning costs [19,20].

Factors affecting the physical and chemical characteristics of asphalt pavements have been mentioned by many researchers in recent years. Some of the most important parameters that may alternate the spectral signatures and color of asphalt pavement are: aging, cracking, raveling, gravels, slurry crack seals, asphalt patches, and chip seal treatments [21]. Traffic, weather wear, and surface distresses can also affect the reflectance of asphalts [2,5]. The color of paved areas is correlated to the loss of bitumen covering the aggregates [2,21]. Thus, according to Norohnha et al. [22], the age of asphalt pavements is correlated to the health of the pavement.

Autelitano and Giuliani, in 2019, [23] intended to show the color appearance of pigmented asphalt surface in daytime and nighttime. They proposed a method of chromatic characterization of colored asphalt pavements considering colored pigmented slurry seals. The equipment used to measure the color of the pavements was a hand-held CM-2500d spectrophotometer (Konica Minolta). This took place on laboratory scale samples at room temperature. The color coordinates were expressed using the 1976 CIE (Commission Internationale de l'éclairage/International Commission on Illumination) $\mathrm{L}^{*} \mathrm{a} * \mathrm{~b}$ color space. The primary outcomes of the study show that the color appearance of the samples is influenced by artificial lighting. In addition, the sodium-vapor lamps made the samples look shadowy black instead of the color registered in daylight and the new generation of metal halide and LED sources to represent the leading options of white lighting [23].

Another study examined the surface color changes of colored asphalt at different ageing periods. The samples used were analyzed in RGB and HSI color spaces. These samples were made of two colors, green and red (with different ratios), and were exposed to ultraviolet (UV) light for five different spans. The results revealed that ageing spans affect the change in the colored asphalt and that the red dye had better resistance to the UV light [24].

There is not much research associated with the colored asphalt pavement [25]; thus, Ning and Huan in 2017 aimed to show the low durability of color on asphalt. They ran long-term rolling and long-term ageing to simulate the vehicle rolling and the ageing performance of asphalt color. The color durability was evaluated through RGB and trace residue formula. The results reveal that a color durable asphalt pavement resists tire traces and improves the color durability of asphalt pavement [25].

Since engineers have, in recent years, shown interest in the effect of the thermal loads of asphalt pavements on their mechanical properties, Pascual-Muñoz et al. (2014) [26] tried to determine the influence of asphalt pavements' early color degradation considering their thermal behavior. The study concerned the thermal behavior and color degradation of the asphalt mixes while they also compared the laboratory samples to access roads of seven low volume car parks. The equipment used to determine the color of the samples was the Konica Minolta CM-600d spectrophotometer. The results revealed that there were large differences in thermal behavior between asphalt with different gradations and densities, and there was a successful simulation of color degradation of asphalt. Several months after opening, asphalt surfaces have an L* (Lightness) value as high as for the next 4-5 years, as far as low 
volume pavements concern. The degradation presented in the paper simulates a six-year-old low volume asphalt pavement. When asphalt suffers from color degradation, there is a slight reduction in temperature and energy collection capacity [26].

In summation, not much work has been done on the characterization of asphalt pavements using their color through simple equipment, such as colorimeters. Thus, this work uses a colorimeter to study the behavior of asphalt pavements. All the colorimetric samples were compared to data taken through a spectroradiometer and then used to find out a separability index in the visible spectrum using the spectral bands of a Very High Resolution (VHR) satellite, such as WorldView 3 (WV3).

A two-way methodology is described in this paper that can provide information on how to compare the two equipment. The first method used a comparison in the CIELAB color space. In other words, the spectroradiometrer data were converted into the CIELAB color space to be compared to the colorimeter ones. The second method compared the reflectance of the asphalt pavements concerning the two different equipment used. Otherwise stated, the colorimetrer data were converted into reflectance data and compared to the spectroradiometrer ones. The latter proves that colorimeters can be used to guide satellites, such as WV3, in the characterization of asphalt pavements in terms of their age. In the end, the study proposes a normalization index that can be used for asphalt pavement age characterization, through a simulation study of the methodology on WV3.

\section{Materials and Methods}

The methodology followed in this study concerned the correlation of the data produced between the two main equipment used, i.e., spectroradiometer and colorimeter. The spectroradiometer produces spectral data, while the colorimeter produces color data (i.e., Lab or RGB). Thus, a two-way comparison between the equipment was used to provide an alternative way to analyze color/spectral data. In other words, after the collection of data (Step 1), the equipment datasets were compared to each other, firstly, by converting the spectroradiometer data into color data (Step 2). Next, data analysis took place using statistical tests such as T-Test, Analysis of Variance (ANOVA) test, and Pearson correlation (Step 3). When the data of the two equipment was proved to be statistically related, the second (vise-versa) conversion took place, i.e., the color data were converted into spectral data (Step 4). An extra step of data analysis took place (Step 5), but this time the spectral data for both equipment went through in-band analysis of WorldView 3 (WV3) and were compared using two separability indices (Euclidean Distance and Mahalanobis Distance). Finally, by applying the results of the methodology, there is a clear characterization of asphalt pavements in terms of their ageing (Step 6). All steps outlined in Figure 1 are described in detail in the following sections of this study.

\subsection{Data Collection}

The study took place in Larnaca, which is located in the southern part of Cyprus island. The selected areas are situated outside the city of Larnaca and are relatively close to each other (less than $2 \mathrm{~km}$ in diameter). All the areas are characterized by low to very low traffic load. The measurements were taken inside a $4 \mathrm{~m}^{2}$ road section situated on one lane of the road, for safety reasons, without taking any asphalt pavement distress into consideration. Since all the sections suffered the same weather conditions and similar traffic load was constructed using the same design manuals, it was considered appropriate to assume that all the variables (e.g. traffic, weather condition etc.) were the same for all areas, except for their age of construction. Data were retrieved from six different asphalt pavements that were paved for three age categories. Two of the areas, A1 and A2, were less than five years old (Age category 1), B1 and B2 were five to ten years old (Age category 2), while C1 and C2 were ten to fifteen years old (Age category 3). The first category indicates newly paved asphalt pavements, while the second category refers to pavements prone to structural defects. The third category illustrates asphalt pavements that have a high possibility of needing maintenance. 


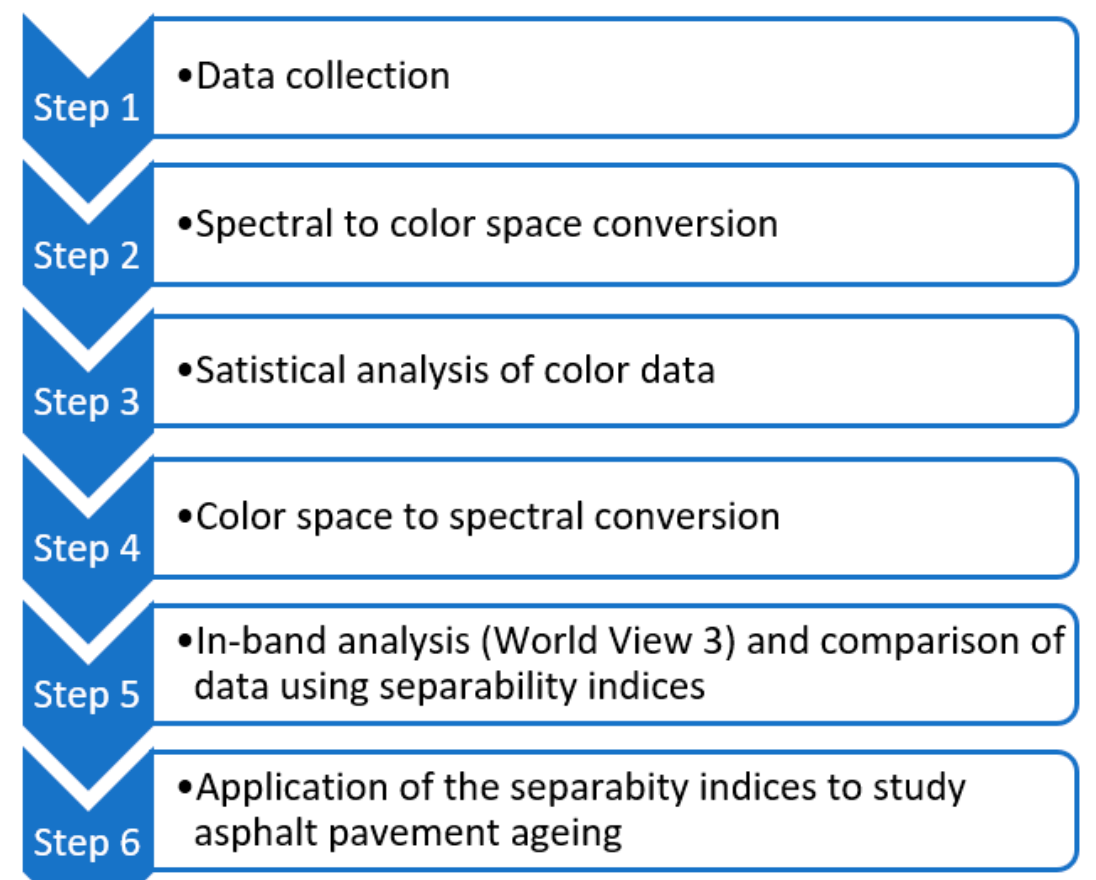

Figure 1. Overall Methodology.

An example of the data collection method is illustrated in Figure 2. In the left of the figure, the red box shows the $4 \mathrm{~m}^{2}$ road section examined, while the right side of the figure shows an example of the data collected inside the $4 \mathrm{~m}^{2}$ road section. The Field Of View (FOV) of the spectroradiometer was $4^{0}$ and the height of observation was $80 \mathrm{~cm}$; thus, the diameter of a spectroradiometer sample was $5.6 \mathrm{~cm}$. Since the diameter of a colorimetric sample was $0.8 \mathrm{~cm}$, it was considered appropriate to use an average value of three colorimetric samples for each spectroradiometric sample, as shown in Figure 2 (right).

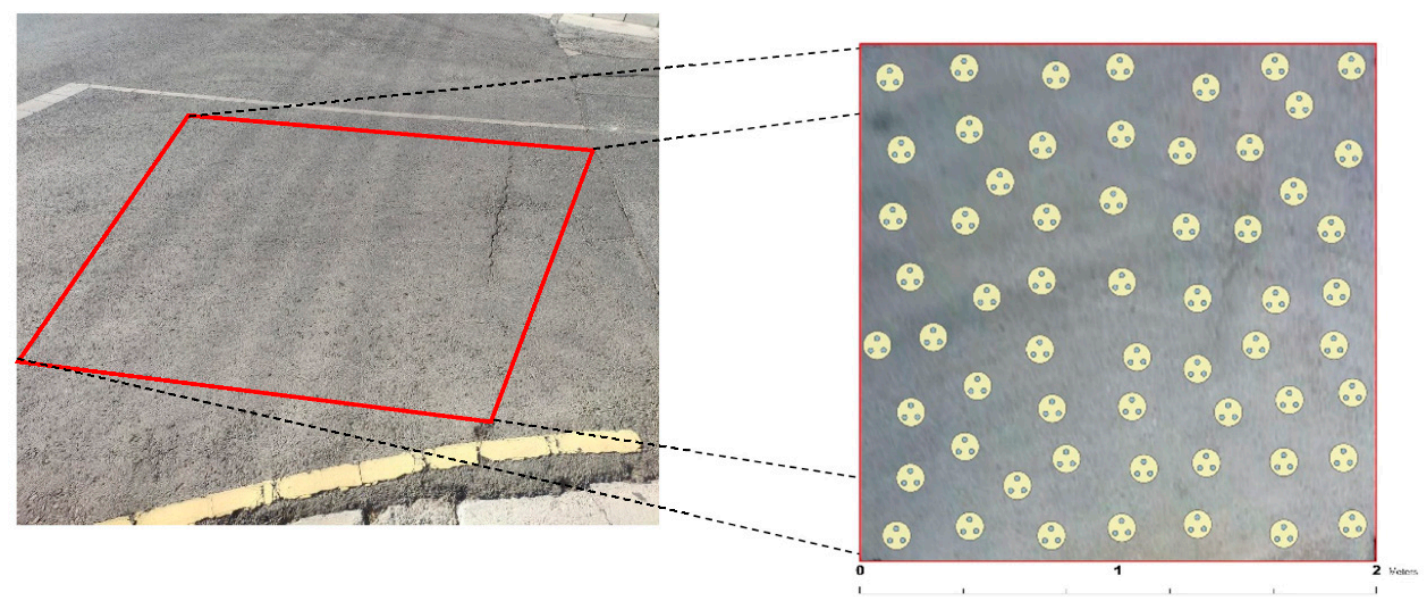

Figure 2. Example of a $4 \mathrm{~m}^{2}$ road section on the left (in red box). Example of Radiometer (yellow dots) and colorimeter (blue dots) dataset collection on the right (in scale).

\subsection{Resources}

Data collection was performed using two main equipment, a spectroradiometer and a colorimeter. The SVC 1024 (Spectra Vista) spectroradiometer (Figure 3a) used has a spectral range of 350-2500 nm using three detectors covering the Visible (V), Near Infrared (NIR), and Short Wave Infrared (SWIR) with 
bandwidths of: $\leq 3.5 \mathrm{~nm}$ for 350-1000 nm, $\leq 3.8 \mathrm{~nm}$ for $1000-1885 \mathrm{~nm}$, and $\leq 2.5 \mathrm{~nm}$ for $1885-2500 \mathrm{~nm}$. The calibration of the spectroradiometer was performed using a spectralon panel assumed to be a Lambertian surface.

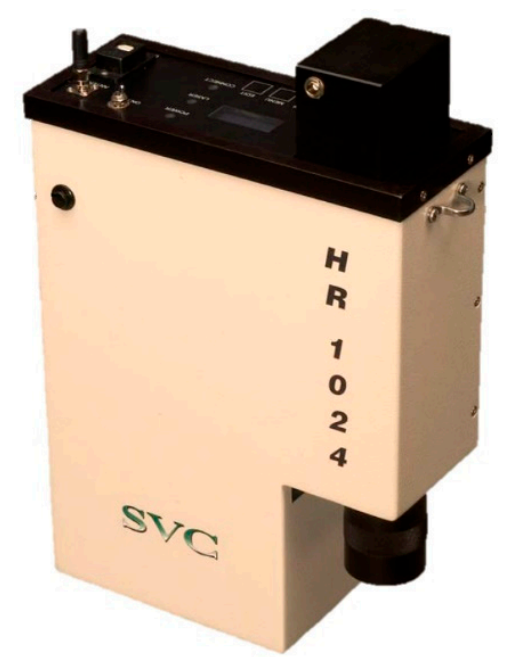

(a)

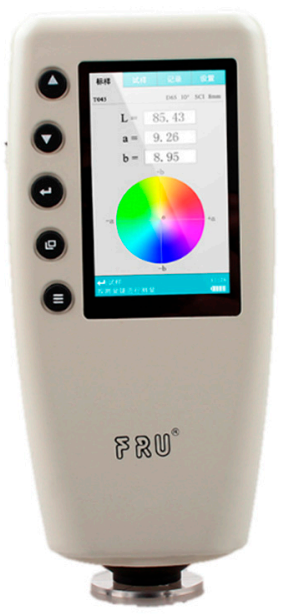

(b)

Figure 3. Spectroradiometer HR 1024 (a) [27] and Colorimeter WR-18 (b) [28].

The colorimeter used was the FRU WR-18 (Figure 3b). It can work with CIELAB, CIELCH, CIEXYZ, and sRGB color spaces and uses its own light source (D65). During this study, L*a*b*, was the main color space used as far as concerns the colorimeter. This color space is widely used, describing all the colors visible human (red-green-blue). The colorimeter was calibrated using white correction mode according to the factory instructions. The CIE standard illuminant D65 is referred to as the daylight illuminant since it represents a relative spectral distribution of daylight. It is broadly used as the nominal correlated color temperature (CCT) of the daylight since it has a CCT of approximately $6500 \mathrm{~K}[23]$.

All the measurements were performed between 10:00 a.m. and 2:00 p.m. during the spring season under clear sky conditions.

After the data collection, conversion of data from spectral to color space took place and then the conversion that took place was the other way around, i.e., the data was converted from color space to spectral. In this way, the outlined methodology provides an additional tool in monitoring asphalt pavements without the use of a spectroradiometer, i.e., by using only a colorimeter. In addition, researchers can have both conversions available for study. The methods were tested with the outlined techniques for asphalt pavement categorization in the visible spectrum.

Since colorimeters are ideal for measuring color space in the visible spectrum, all the studied data were in the range of $400-830 \mathrm{~nm}$. Thus, the spectroradiometer data ranging from $831 \mathrm{~nm}$ to $2500 \mathrm{~nm}$ were neglected. In addition, the extreme measurements were not considered, while for each equipment (radiometer, colorimeter), 50 samples were examined in each road section with area of $4 \mathrm{~m}^{2}$, while extra $15 \%$ of the samples were used for validation purposes. The detailed procedure for the conversion of spectral data to color space is described below.

\subsection{Spectral to $L^{*} a^{*} b^{*}$ Color Space}

To convert the spectral values, measured in the field, to color space CIE $\mathrm{L}^{*} \mathrm{a}^{*} \mathrm{~b}^{*}$, an intermediate conversion took place, to the CIE XYZ trichromatic system [29,30]. In other words, the spectral values for the spectroradiometer were firstly converted to $X Y Z$ and finally to $L^{*} a^{*} b^{*}$. According to Schanda (2007) [31], color is a perception that is not accessible to engineering measurements; 
thus, CIE colorimetry is used as the metric of the color stimulus. The formulae used for this conversion are as follows:

2.3.1. Spectral to $X Y Z$ Trichromatic System

$$
\begin{gathered}
\Phi(\lambda)=S(\lambda) I(\lambda) \\
X=k \int_{\min \lambda}^{\max \lambda} \Phi(\lambda) \bar{x}(\lambda) d \lambda \\
Y=k \int_{\min \lambda}^{\max \lambda} \Phi(\lambda) \bar{y}(\lambda) d \lambda \\
Z=k \int_{\min \lambda}^{\max \lambda} \Phi(\lambda) \bar{z}(\lambda) d \lambda \\
k=\frac{1}{\int_{\min \lambda}^{\max \lambda} \Phi(\lambda) \bar{z}(\lambda) d \lambda}
\end{gathered}
$$

where $\lambda$ is the wavelength in $\mathrm{nm}, k$ is a constant, $\Phi(\lambda)$ is the relative color stimulus function (since the colorimeter uses a CIE standard illuminant D65), $S(\lambda)$ is the spectral reflectance factor of the sample, $I(\lambda)$ is the relative spectral power distribution of the illuminant (D65), $\bar{x}, \bar{y}, \bar{z}$ are the CIE 1964 standard observer functions $\left(10^{\circ}\right.$ visual field)

Based on CIE [30], the above equations are replaced by numerical summations as follows:

$$
\begin{aligned}
X & =k \sum_{i} \Phi(\lambda) \bar{x}(\lambda) d \lambda \\
Y & =k \sum_{i} \Phi(\lambda) \bar{y}(\lambda) d \lambda \\
Z & =k \sum_{i} \Phi(\lambda) \bar{z}(\lambda) d \lambda \\
k & =\frac{1}{\sum_{i} I(\lambda) \bar{y}(\lambda) d \lambda}
\end{aligned}
$$

The wavelength used was $400 \mathrm{~nm}$ to $830 \mathrm{~nm}$, while the sample spacing was $5 \mathrm{~nm}$.

\subsubsection{XYZ Trichromatic System to CIE L*a*b*}

During the CIE progress report in London, in 1975, the CIE Technical Committee recommended the use of two uniform color spaces, CIELAB and CIELUV [32]. The WR-18 colorimeter uses a visual angle of $10^{\circ}$; thus, the CIELAB color space should be combined with the CIE 1964 standard colorimetric observer.

The conversion from $X Y Z$ to CIE $1976\left(\mathrm{~L}^{*} \mathrm{a}^{*} \mathrm{~b}^{*}\right)$ took place using the following equations:

$$
\begin{gathered}
L^{*}=116 f\left(\frac{Y}{Y_{r}}\right)-16 \\
a^{*}=500\left(f\left(\frac{X}{X_{r}}\right)-f\left(\frac{Y}{Y_{r}}\right)\right) \\
b^{*}=200\left(f\left(\frac{Y}{Y_{r}}\right)-f\left(\frac{Z}{Z_{r}}\right)\right)
\end{gathered}
$$

where:

$$
f\left(\frac{X}{X_{r}}\right)=\sqrt[3]{\left(\frac{X}{X_{r}}\right)} \text { if }\left(\frac{X}{X_{r}}\right)>0.008856 \text { (based on CIE standard) }
$$


Otherwise:

$$
f\left(\frac{X}{X_{r}}\right)=\frac{k\left(\frac{X}{X_{r}}\right)+16}{116} \text { if }\left(\frac{X}{X_{r}}\right) \leq 0.008856 f\left(\frac{Y}{Y_{r}}\right)=\sqrt[3]{\left(\frac{Y}{Y_{r}}\right)} \text { if }\left(\frac{Y}{Y_{r}}\right)>0.008856
$$

Otherwise:

$$
f\left(\frac{Y}{Y_{r}}\right)=\frac{k\left(\frac{Y}{Y_{r}}\right)+16}{116} \text { if }\left(\frac{Y}{Y_{r}}\right) \leq 0.008856 f\left(\frac{Z}{Z_{r}}\right)=\sqrt[3]{\left(\frac{Z}{Z_{r}}\right)} \text { if }\left(\frac{Z}{Z_{r}}\right)>0.008856
$$

Otherwise:

$$
f\left(\frac{Z}{Z_{r}}\right)=\frac{k\left(\frac{Z}{Z_{r}}\right)+16}{116} \text { if }\left(\frac{Z}{Z_{r}}\right) \leq 0.008856 k=903.3 \text { (based on CIE standard) }
$$

$X, Y, Z$ presented in the above equations are the tristimulus values of the testing sample while $\mathrm{Xr}, \mathrm{Yr}, \mathrm{Zr}$ are the tristimulus values of the white reference.

\subsection{Analysis of the Color Data}

The spectroradiometer data was converted to $L^{*} \mathrm{a}^{*} \mathrm{~b}^{*}$ and compared to the colorimeter's data. For this study, $\mathrm{L}^{*}$ (i.e., lightness) was the basis of comparison of the two equipment. This comparison can be considered as a validation of the colorimeter data. Next, the data of the two equipment were compared statistically using T-test, ANOVA, and Pearson correlation.

\subsection{From Color Space to Reflectance}

Since the first step of the methodology was considered successful, the vice versa (i.e., the conversion from color space to reflectance) conversion is essential as well. The reflectance of an object is a parameter that can be used in many remote sensing techniques. The purpose of this work was to use a colorimeter as a ground validation tool of remote sensing data i.e., satellite data. Since satellites use spectral bands, the ideal scenario was to use a colorimeter (instead of a spectroradiometer) in combination with an in-band analysis of satellite data to classify asphalt pavements in terms of their age.

The color space to reflectance conversion was performed as per the conversion methods of Burns (2020) [33]. Numerical methods can be used to reconstruct a reflectance distribution from a set of tristimulus values, $X Y Z$. The study used the method that is intended to be used on object colors. Burns (2020) [33] claimed that this method provides the best match with minimum root mean square errors compared to other numerical methods and guarantees a reflectance value between 0 and 1 . This is achieved by using a hyperbolic tangent change of variables. The transformation function used is defined as follows:

$$
\rho=\frac{\tanh (z)+1}{2}
$$

where $\rho$ is the reflectance distribution ranging from 0 to 1 , tanh is the hyperbolic tangent ranging from -1 to 1 .

The above function is divided by two to generate reflectance within the 0 to 1 range. The smoothest line comes through the minimum of the quadratic function of $z$ :

$$
\begin{gathered}
\min \frac{1}{2} z^{\prime} D z \\
\text { s.t. } \frac{A_{w}^{\prime}(\tanh (z)+1)}{2}=X Y Z_{W}
\end{gathered}
$$


where $D$ is an $n \times n$ matrix of finite-differencing constants: $D=\left[\begin{array}{ccccccc}2 & -2 & & & & \\ -2 & 4 & -2 & & & \\ & -2 & 4 & -2 & & \\ & \ddots & \ddots & \ddots & \\ & & -2 & 4 & -2 \\ & & & & -2 & 2\end{array}\right]$. $A$ is an $n \times 3$ array of color matching functions (CMFs), $A=[\bar{x}, \bar{y}, \bar{z}], A_{w}$ is the illuminant (W) color matching functions (CMFs) computed as $\bar{W} A, \bar{W}$ is an $n \times n$ matrix with $\mathrm{W}$ on the main diagonal and zeros elsewhere,, is the transpose of the matrix

An assumption taken into consideration is that the scalar product $\bar{y}^{\prime} \times W=1$, due to illuminant normalization. This a common practice used in previous studies as well [33-35]. The derivative $(\tanh (z)+1)$ is $\left(\operatorname{sech}^{2}(z)\right)$ and $\lambda$ is a $(3 \times 1)$ vector of Lagrande multipliers, thus by applying the Lagrange multipliers function, the stationary conditions would be:

$$
F=\left\{\begin{array}{c}
D z+\operatorname{diag}\left(\frac{\operatorname{sech}^{2}(z)}{2}\right) A_{w} \lambda \\
A_{w}^{\prime}\left(\frac{\tanh (z)+1}{2}\right)-X Y Z_{w}
\end{array}\right\}
$$

$F$ matrix is associated with the Jacobian matrix $J$, which is its first partial derivative:

$$
J=\left[\begin{array}{cc}
D-\operatorname{diag}\left(\operatorname{diag}\left(\operatorname{sech}^{2}(z) \tanh (z)\right) A_{w} \lambda\right) & \operatorname{diag}\left(\frac{\operatorname{sech}^{2}(z)}{2}\right) A_{w} \\
A_{w}^{\prime} \operatorname{diag}\left(\frac{\operatorname{sech}^{2}(z)}{2}\right) & 0
\end{array}\right]
$$

Note that the derivative of $\frac{\operatorname{sech}^{2}(z)}{2}$ is $\left(-\operatorname{sech}^{2}(z) \tanh (z)\right)$. In each iteration, the change in the variables is found by solving the linear system:

$$
J\left\{\begin{array}{c}
\Delta z \\
\Delta \lambda
\end{array}\right\}=-F
$$

For all the iterations, the values of $z$ and $\lambda$ are updated using:

$$
\begin{aligned}
& z^{k+1}=z^{k}+\Delta z \\
& \lambda^{k+1}=\lambda^{k}+\Delta \lambda
\end{aligned}
$$

\subsection{Analysis of the Spectral Data}

Since there are reflectance data from the spectroradiometer and the colorimeter, in-band analysis of WorldView 3 (WV3) was used to identify the suitable bands for the age classification of asphalt pavements. Relative Spectral Response (RSR) of WV3 was used to calculate the value of each band for the studied asphalt pavements as in Figure 4. A mean value of each examined WV3 band, for both equipment, was calculated, using the RSRs of the satellite sensors [36-38].

WV3 consists of one panchromatic band (450-800 nm), eight multispectral bands (400-1040 nm), eight Short Wave Infrared (SWIR) bands (1195-2365 nm), and 12 CAVIS (Clouds, Aerosols, Vapors, Ice and Snow) bands (405-2245 nm). For the study of asphalt pavements, high accuracy is needed, i.e., high resolution, thus only the multispectral bands were used, which have a resolution of $1.24 \mathrm{~m}$ at Nadir (1.38 $\mathrm{m}$ at $20^{\circ}$ Off-Nadir). The multispectral bands of WV3 are the Coastal band (with a central wavelength of $427.4 \mathrm{~nm}$ ), the Blue band (with a central wavelength of $481.9 \mathrm{~nm}$ ), the Green band (with a central wavelength of $547.1 \mathrm{~nm}$ ), the Yellow band (with a central wavelength of $604.3 \mathrm{~nm}$ ), the Red band (with a central wavelength of $660.1 \mathrm{~nm}$ ), the Red-edge band (with a central wavelength of $722.7 \mathrm{~nm}$ ), the NIR 1 band (with a central wavelength of $824.0 \mathrm{~nm}$ ), and the NIR 2 band (with 
a central wavelength of $913.6 \mathrm{~nm}$ ) [38]. The colorimeter data is compatible with the 6 (out of 8) multispectral bands of WV3 i.e., Coastal (band 1), Blue (band 2), Green (band 3), Yellow (band 4), Red (band 5), and Red-edge (band 6); thus, only these bands were examined in this work. After getting the values for the six WV3 bands for the three asphalt pavement categories using in-band analysis, combinations between the categories and the bands were made using separability indices for both pieces of equipment. The separability indices used were the Euclidean distance method and the Mahalanobis distance method.

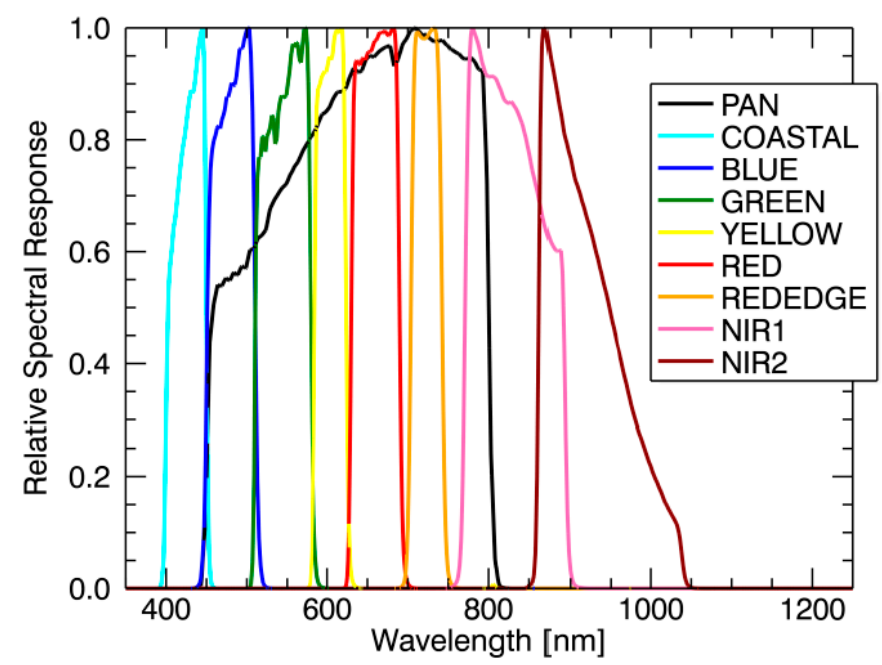

Figure 4. WorldView-3 Relative Spectral Radiance Response (nm) for the VNIR bands [38].

The Euclidean distance accounts equally for each measurement taken and is used in many studies to measure similarity [39-41]. The data are assumed to be of the same importance and independent from others [42]. The equation used in the study is as follows:

Euclidean distance method:

$$
d_{e}=\left(p_{x}-q_{x}\right)
$$

where $d_{e}$ is the Euclidean distance between reflectance values measured as $\%, p_{x}$ is the reflectance in a specific wavelength (satellite band) for a group (pavement category) of observations measured as $\%, q_{x}$ is the reflectance in a specific wavelength (satellite band) for a different group (pavement category of observations measured as \%.

Mahalanobis distance [43] measures the distance of a point towards the distribution of points in a multidimensional space [44]. In this study, it deals with the correlations between datasets and their variability. It weighs each measurement differently using the range of variability [45]. The data accounting for high variability receive less weight than the ones with low variability [42]. The Mahalanobis distance equation used is as follows:

$$
d_{m}=\sqrt{\left(\overline{s_{x}}-\overline{t_{x}}\right) \times C^{-1} \times\left(\overline{s_{x}}-\overline{t_{x}}\right)^{\prime}}
$$

where $d_{m}$ is the Mahalanobis distance, $\overline{s_{x}}$ is a vector in a specific wavelength (satellite band) for a group (pavement category) of observations, $\overline{t_{x}}$ is a vector in a specific wavelength (satellite band) for a different group (pavement category) of observations, $C$ is the covariance matrix.

\subsection{Application}

The above two separability indices were used to observe if the spectroradiometer data were in line with the colorimeter data based on satellite visible bands. Since for both pieces of equipment, the results were in line, an application of data took place in order to visualize asphalt pavements in terms of their age category. After the conversion of the colorimetric data to reflectance values 
using the RSR of WV3, there were 50 colorimetric measurements for each one of the six WV3 bands studied. The visualization of the reflectance and the normalization equation/filter values was achieved using interpolation. The ArcGIS software was used for the application of data using a kriging interpolation tool, which works through the correlation between the surrounding values' distance and the values located around a point [46,47]. It should be noted that this can be considered a starting point of the described methodology since it took place in a small region without any satellite image. Thus, no geometric or radiometric correction was made. It is a first step towards the upscaling of radiometric and colorimetric data to satellite data.

\section{Results and Discussion}

As mentioned in the methodology section of the study, the data collected from the spectroradiometer were converted into color space $\mathrm{L}^{*} \mathrm{a}^{*} \mathrm{~b}^{*}$. Since " $\mathrm{L}^{*}$ " stands for the lightness of a color, it can be used to categorize the asphalt pavements in terms of their age. This is true for pavements that undergo similar life usage conditions (i.e. traffic loads, weather conditions, etc.), except from their age of construction. As asphalt pavement undergoes ageing, the lightness of the color of asphalt increases as well. The results concerning the $L^{*}$ of the asphalt pavements can be seen in Figure 5 . The two charts represent the $L^{*}$ data taken using a spectroradiometer (a) and colorimeter (b) for each of the six case studies. The spread out of the data is represented using boxplots that show maximum, minimum, median values and 1 st, 3 rd quartiles of the data. $L^{*}$ observed from colorimeter data seems to be underestimated compared to the spectroradiometer $\mathrm{L}^{*}$ values. In general, the behavior of the equipment is very similar since there is an increase, as expected, in lightness as the ageing of asphalt pavements increases. In other words, study area A (Age Category 1 ) has the minimum $L^{*}$ values, whereas study area $C$ (Age Category 3 ) has the maximum values of $L^{*}$. Age category 2, i.e., study area $B$, has intermediate values, as expected.

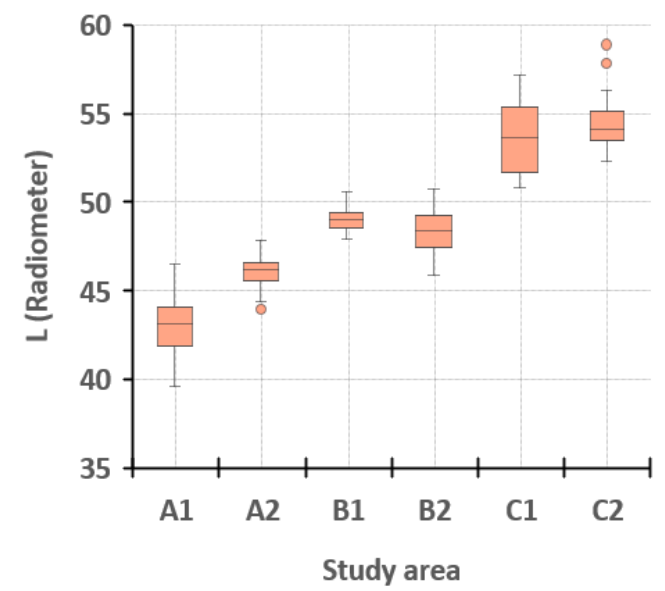

(a)

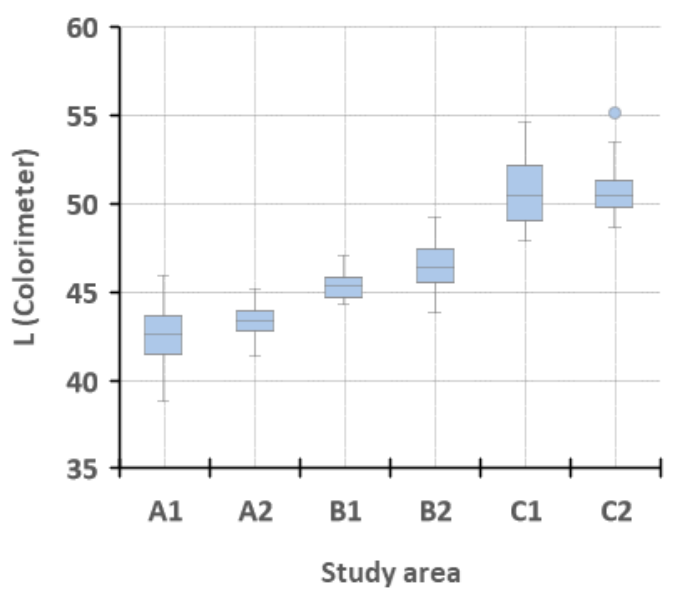

(b)

Figure 5. $L^{*}$ values after spectroradiometer (a) and colorimeter $(\mathbf{b})$ measurements over the study area.

The T-test performed during the study (Tables 1 and 2) revealed that there is no possibility (i.e., $p<0.05$ ) for the data to be mismatched between the three categories. For example, it is not possible for the dataset of study area $C$ to fall inside the dataset range of study area B. In addition, another statistical test was carried out to justify that there is no possibility (i.e., $p<0.05$ ) to mismatch the data between the three categories. This was the Analysis of Variance (ANOVA) test. Again, the p-values were extremely small, revealing that there is no possibility of divergence of the data between the three categories (Tables 3 and 4). 
Table 1. T-Test ( $p$-value) of spectroradiometer data for study areas (age categories) A, B, C.

\begin{tabular}{cccc}
\hline Spectroradiometer & A & B & C \\
\hline A & 1 & $3.58 \times 10^{-41}$ & $4.72 \times 10^{-89}$ \\
B & $3.58 \times 10^{-41}$ & 1 & $3.12 \times 10^{-60}$ \\
C & $4.72 \times 10^{-89}$ & $3.12 \times 10^{-60}$ & 1 \\
\hline
\end{tabular}

Table 2. T-Test ( $p$-value) of colorimeter data for study areas (age categories) A, B, C.

\begin{tabular}{cccc}
\hline Colorimeter & A & B & C \\
\hline A & 1 & $6.06 \times 10^{-41}$ & $1.10 \times 10^{-89}$ \\
B & $6.06 \times 10^{-41}$ & 1 & $1.83 \times 10^{-56}$ \\
C & $1.10 \times 10^{-89}$ & $1.83 \times 10^{-56}$ & 1 \\
\hline
\end{tabular}

Table 3. ANOVA test ( $p$-value) of spectroradiometer data for study areas (age categories) A, B, C.

\begin{tabular}{cccc}
\hline Spectroradiometer & A & B & C \\
\hline A & 1 & $7.62 \times 10^{-45}$ & $1.92 \times 10^{-89}$ \\
B & $7.62 \times 10^{-45}$ & 1 & $1.59 \times 10^{-65}$ \\
C & $1.92 \times 10^{-89}$ & $1.59 \times 10^{-65}$ & 1 \\
\hline
\end{tabular}

Table 4. ANOVA test ( $p$-value) of colorimeter data for study areas (age categories) A, B, C.

\begin{tabular}{cccc}
\hline Colorimeter & A & B & C \\
\hline A & 1 & $6.01 \times 10^{-41}$ & $1.86 \times 10^{-92}$ \\
B & $6.01 \times 10^{-41}$ & 1 & $5.93 \times 10^{-58}$ \\
C & $1.86 \times 10^{-92}$ & $5.93 \times 10^{-58}$ & 1 \\
\hline
\end{tabular}

The following graphs (Figure 6) represent the Pearson correlation between the data of the spectroradiometer and the colorimeter. The correlation between the equipment is very high. In all areas, the equipment data are correlated to each other more than $90 \%$.

The above statistical results reveal that the data of the two equipment are in line as far as lightness $\left(L^{*}\right)$ concerns when comparing the color spaces of the two equipment.

An extra $15 \%$ of the test samples for both equipment were used to validate the calibrated $L^{*}$ value of the colorimeter using the equation of the 50 sets. The validation plots can be seen in Figure 7. Table 5 indicates that, again, there is a very high correlation (more than $90 \%$ ) between the two equipment as a result of the validation plots of $L^{*}$ produced. The Root Mean Square Error (RMSE) between radiometric $L^{*}$ values and the calibrated colorimeter values $\left(L_{c a l}\right)$ ranges from 0.5 to 1.07 (Table 5).

Since the analysis of spectral data is very important in remote sensing technologies, it was considered appropriate to convert all the data into spectral data and compare them together using separability indices, as mentioned above.

As far as the conversion of color data to spectral data is concerned, the charts formed are shown in Figures 8 and 9. Both charts are in line with the $L^{*}$ values of Figure 5. In other words, there is an underestimation of data in using the colorimeter. The main objective of the charts was to prove that they are in line with the literature, i.e., as the age of asphalt pavements increases, the reflectance curves are shifting upwards. The reflectance chart produced using the colorimeter data is similar to the chart produced using the spectroradiometer data. The only part that undergoes some differences is mainly in the area of $420-460 \mathrm{~nm}$. To confirm that the differences between the two datasets do not affect the analysis of satellite data in the case that a colorimeter is used for ground truth data, the two datasets are compared using the two separability indices, the Euclidean and the Mahalanobis Distances.

After the implementation of an in-band analysis using the spectral responses of the WV3 bands that are in the visible spectrum, Table 6 was created. The Euclidean distance of the spectroradiometer and colorimeter was found by comparing the six spectral bands (visible spectrum) of WV3. The largest (Euclidean) distance, which indicates the best separability between two asphalt pavements of different 
ageing of construction, is indicated when comparing band 1 and band 6 (WV3). All six tables presented in Table 6 have the same Euclidean distance cell (red color). Thus, using this the Euclidean distance method, the colorimeter and spectroradiometer data are in line and can be used as ground truth data in remote sensing techniques.

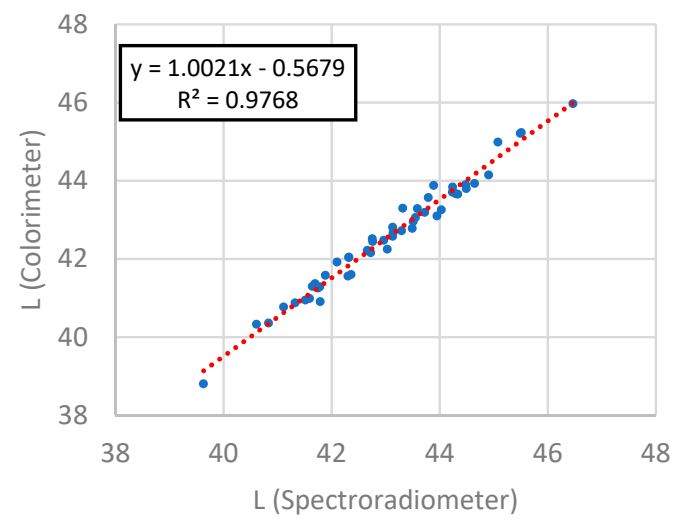

(a)

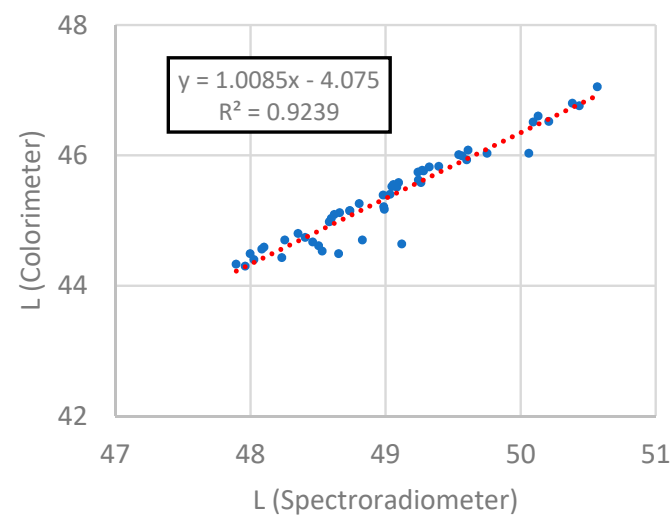

(c)

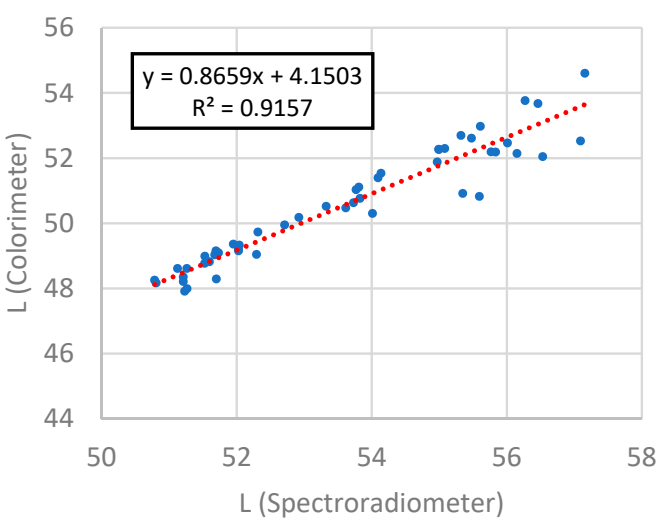

(e)

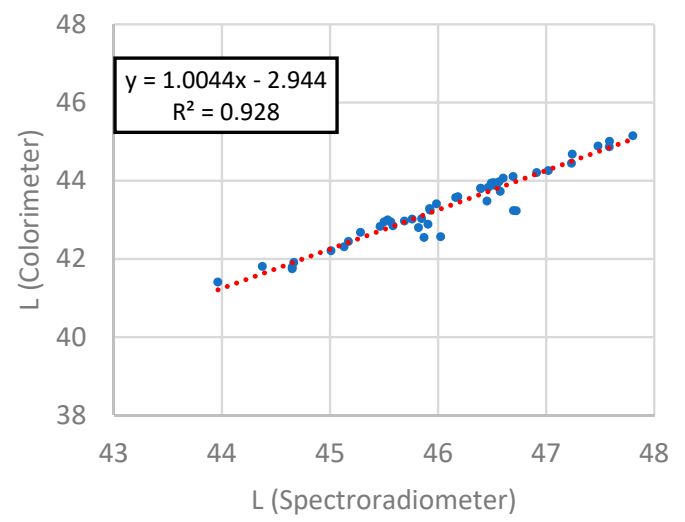

(b)

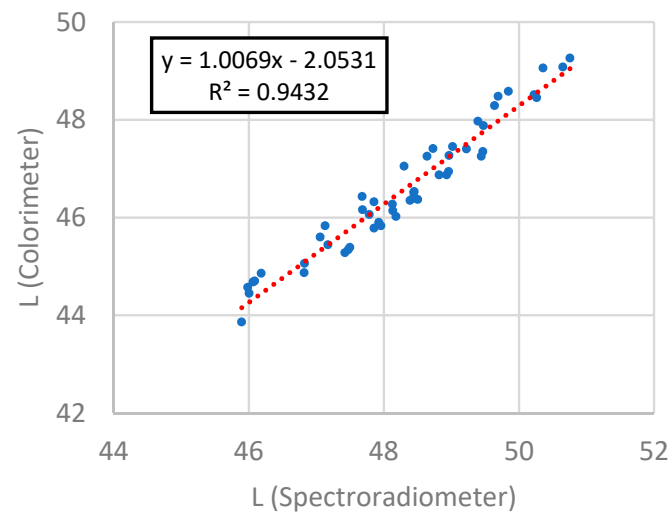

(d)

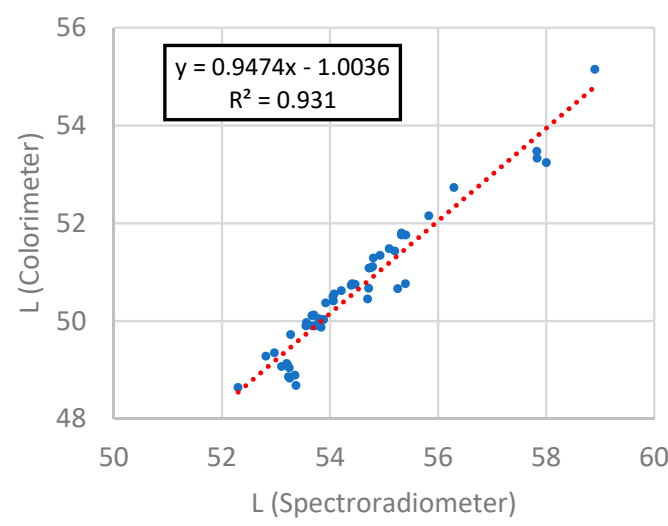

(f)

Figure 6. Correlation plots for each study area between colorimeter and spectroradiometer data for Study Area A1 (a), Study Area A2 (b), Study Area B1 (c), Study Area B2 (d), Study Area C1 (e), Study Area C2 (f). 


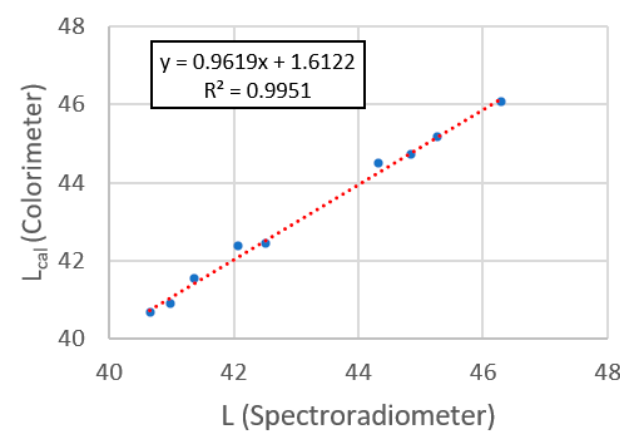

(a)

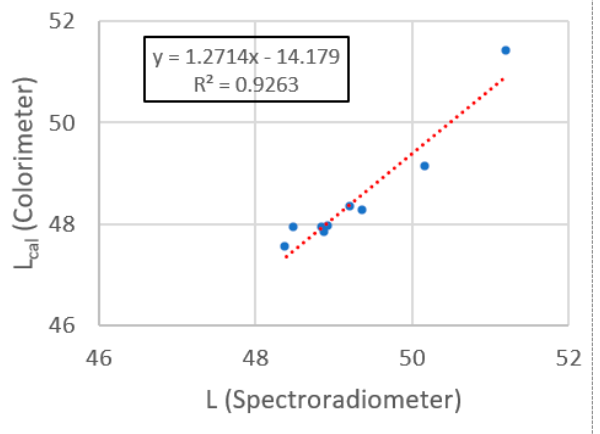

(c)

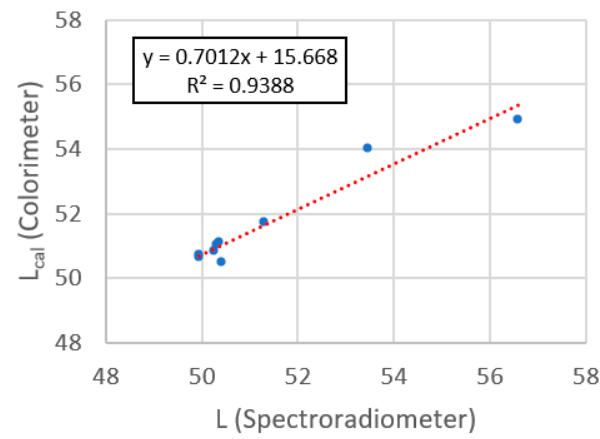

(e)

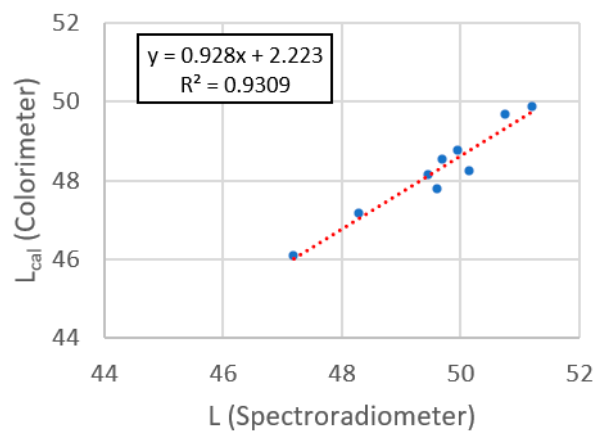

(b)

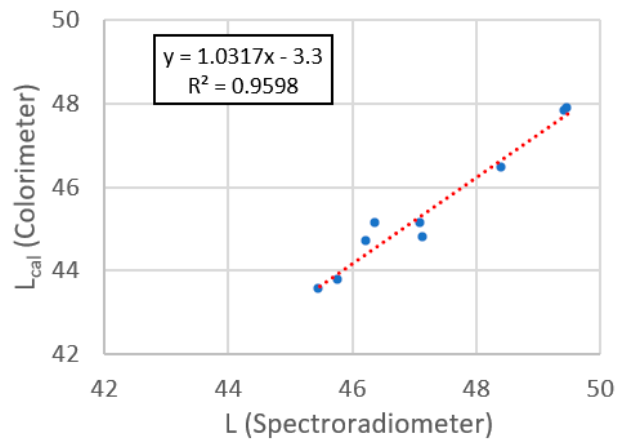

(d)

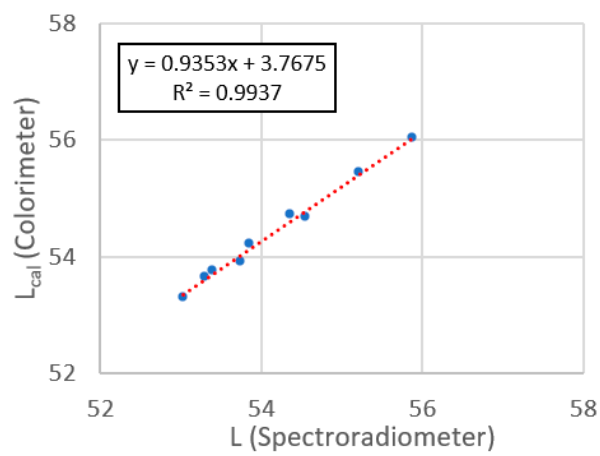

(f)

Figure 7. Validation plots for each study area between calibrated colorimeter data and spectroradiometer data for Study Area A1 (a), Study Area A2 (b), Study Area B1 (c), Study Area B2 (d), Study Area C1 (e), Study Area C2 (f).

Table 5. $\mathrm{R}^{2}$ and RMSE produced through validation plots.

\begin{tabular}{ccc}
\hline Area of Study & $\mathbf{R}^{\mathbf{2}}$ & RMSE (L) \\
\hline A1 & 0.995 & 0.15 \\
\hline A2 & 0.931 & 1.07 \\
\hline B1 & 0.926 & 0.94 \\
\hline B2 & 0.960 & 0.29 \\
\hline C1 & 0.939 & 0.80 \\
\hline C2 & 0.994 & 0.50 \\
\hline
\end{tabular}




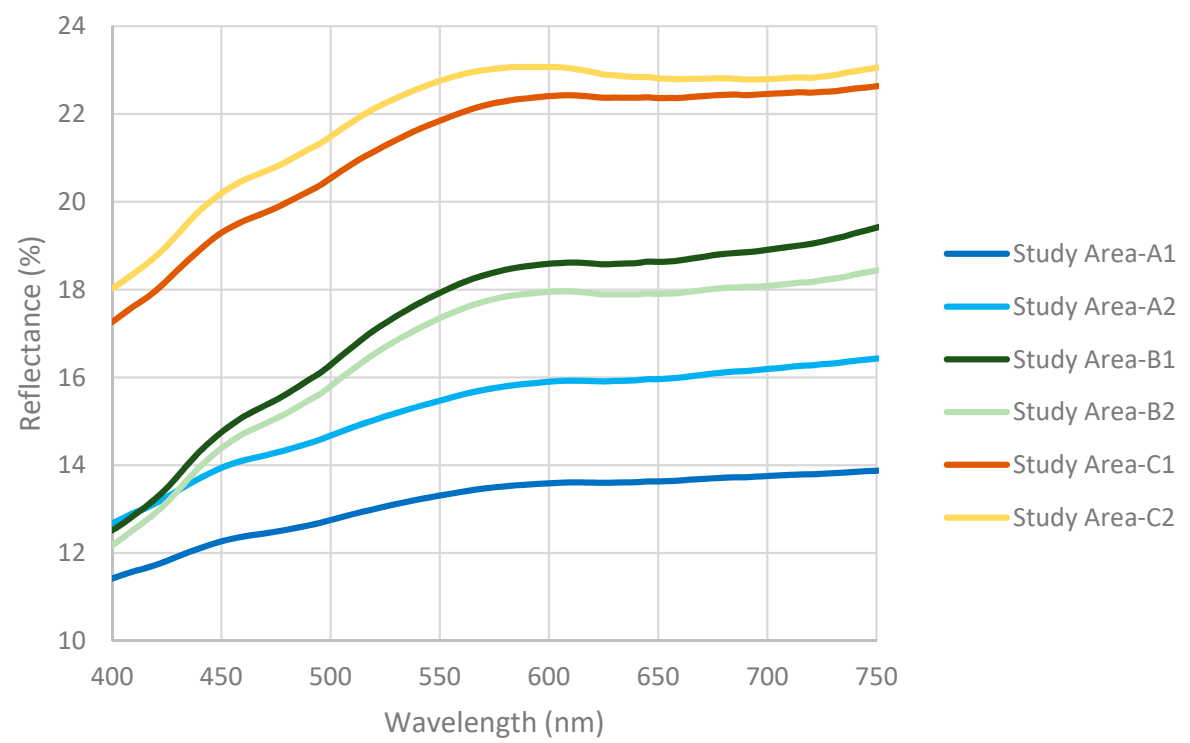

Figure 8. Spectral data of spectroradiometer for areas A1-C2.

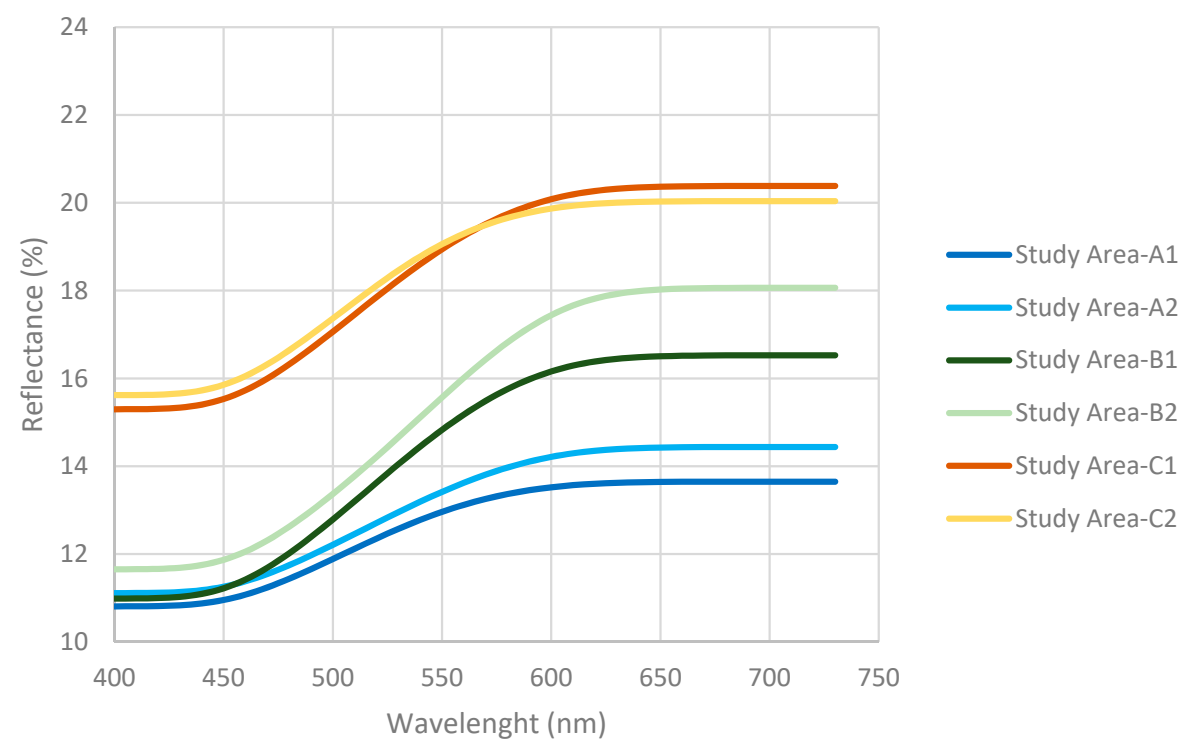

Figure 9. Spectral data of colorimeter (after conversion) for areas A1-C2.

Mahalonobis distance (Table 7) was also used as a separability index between two asphalt pavement categories since it can measure the distance between points and distribution of points. It was considered appropriate to use it in the study since there are cases, especially in old pavements, where the data distribution is large. The results show that the two types of equipment have very similar indications. When compared to the results of Euclidean distance, there are some small alterations in the oldest pavements (i.e., Age category 3) between the satellite bands. In general, again, the combination of band 1 and band 6 is sufficient for all asphalt pavement categories' comparison and can be used as the separability index. The fact that the Mahalanobis distance between WV3 bands is almost the same as the two equipment is of significant interest because this indicates that colorimeter data can be used as ground truth data for the classification of asphalt pavements in terms of their age.

After the implementation of the above new techniques, a grid was created for each asphalt pavement examined using the spectroradiometer/colorimeter data. The visualization of the results, for each WV3 band examined, can be seen in the following figure (Figure 10). The reflectance difference between age categories is obvious in all WV3 bands examined. Thus, the three asphalt 
pavement categories can be separated, as a starting step, using the reflectance values in each satellite band. The green, yellow, and orange colors created represent study area (Age categories) A1, B1, and $\mathrm{C} 1$, respectively.

Table 6. Euclidean distance of WV3 bands in the visible spectrum for spectroradiometer (left) and colorimeter (right).

\begin{tabular}{|c|c|c|c|c|c|c|c|c|c|c|c|c|c|}
\hline \multicolumn{7}{|c|}{ Spectroradiometer } & \multicolumn{7}{|c|}{ Colorimeter } \\
\hline & B1 & B2 & B3 & B4 & B5 & B6 & & B1 & $\mathrm{B} 2$ & B3 & B4 & B5 & B6 \\
\hline A1 & 1.8 & 3.8 & 5.9 & 6.7 & 6.8 & 7.2 & A1 & 0.2 & 1.3 & 3.8 & 5.3 & 5.7 & 5.7 \\
\hline $\mathrm{A} 2$ & 1.1 & 3.1 & 5.2 & 6.0 & 6.1 & 6.5 & $\mathrm{~A} 2$ & 0.4 & 0.6 & 3.2 & 4.7 & 5.0 & 5.0 \\
\hline A3 & 0.4 & 2.4 & 4.5 & 5.3 & 5.4 & 5.8 & $\mathrm{~A} 3$ & 1.8 & 0.7 & 1.8 & 3.3 & 3.6 & 3.7 \\
\hline A4 & 0.0 & 2.1 & 4.2 & 5.0 & 5.1 & 5.4 & $\mathrm{~A} 4$ & 2.5 & 1.4 & 1.1 & 2.7 & 3.0 & 3.0 \\
\hline A5 & 0.0 & 2.0 & 4.1 & 4.9 & 5.0 & 5.4 & A5 & 2.6 & 1.5 & 1.0 & 2.5 & 2.9 & 2.9 \\
\hline \multirow[t]{2}{*}{ A6 } & 0.2 & 1.9 & 4.0 & 4.8 & 4.9 & 5.2 & A6 & 2.6 & 1.5 & 1.0 & 2.5 & 2.9 & 2.9 \\
\hline & $\mathrm{C} 1$ & $\mathrm{C} 2$ & C3 & C4 & C5 & C6 & & C1 & $\mathrm{C} 2$ & C3 & C4 & C5 & C6 \\
\hline B1 & 4.7 & 6.4 & 8.1 & 8.8 & 8.8 & 8.9 & B1 & 4.3 & 5.4 & 7.7 & 9.1 & 9.3 & 9.3 \\
\hline B2 & 2.6 & 4.3 & 6.0 & 6.7 & 6.7 & 6.8 & B2 & 3.2 & 4.3 & 6.7 & 8.0 & 8.2 & 8.3 \\
\hline B3 & 0.5 & 2.3 & 4.0 & 4.6 & 4.6 & 4.7 & B3 & 0.7 & 1.7 & 4.1 & 5.4 & 5.7 & 5.7 \\
\hline B4 & 0.3 & 1.5 & 3.2 & 3.8 & 3.8 & 3.9 & B4 & 0.8 & 0.2 & 2.6 & 3.9 & 4.2 & 4.2 \\
\hline B5 & 0.4 & 1.4 & 3.0 & 3.7 & 3.7 & 3.8 & B5 & 1.1 & 0.1 & 2.3 & 3.6 & 3.9 & 3.9 \\
\hline \multirow[t]{2}{*}{ B6 } & 0.7 & 1.0 & 2.7 & 3.4 & 3.4 & 3.5 & B6 & 1.2 & 0.1 & 2.3 & 3.6 & 3.8 & 3.9 \\
\hline & $\mathrm{C} 1$ & $\mathrm{C} 2$ & C3 & C4 & C5 & C6 & & $\mathrm{C} 1$ & $\mathrm{C} 2$ & C3 & C4 & C5 & C6 \\
\hline A1 & 6.5 & 8.2 & 9.9 & 10.5 & 10.5 & 10.6 & A1 & 4.5 & 5.6 & 7.9 & 9.3 & 9.5 & 9.5 \\
\hline $\mathrm{A} 2$ & 5.8 & 7.5 & 9.2 & 9.8 & 9.8 & 9.9 & $\mathrm{~A} 2$ & 3.9 & 4.9 & 7.3 & 8.6 & 8.9 & 8.9 \\
\hline A3 & 5.1 & 6.8 & 8.5 & 9.1 & 9.1 & 9.2 & A3 & 2.5 & 3.6 & 5.9 & 7.2 & 7.5 & 7.5 \\
\hline A4 & 4.7 & 6.5 & 8.2 & 8.8 & 8.8 & 8.9 & A4 & 1.8 & 2.9 & 5.3 & 6.6 & 6.8 & 6.9 \\
\hline A5 & 4.7 & 6.4 & 8.1 & 8.7 & 8.7 & 8.8 & A5 & 1.7 & 2.8 & 5.1 & 6.5 & 6.7 & 6.7 \\
\hline A6 & 4.5 & 6.3 & 7.9 & 8.6 & 8.6 & 8.7 & A6 & 1.7 & 2.8 & 5.1 & 6.5 & 6.7 & 6.7 \\
\hline
\end{tabular}

$\mathrm{A}, \mathrm{B}$ and $\mathrm{C}$ indicate the category of asphalt pavement

Numbers " $1-6$ " indicate WV3 bands

Green: Small distance $\quad$ Red: Large distance

Table 7. Mahalanobis distance of WV3 bands in the visible spectrum for spectroradiometer (left) and colorimeter (right).

\begin{tabular}{|c|c|c|c|c|c|c|c|c|c|c|c|c|c|}
\hline \multicolumn{7}{|c|}{ Spectroradiometer } & \multicolumn{7}{|c|}{ Colorimeter } \\
\hline & B1 & B2 & B3 & B4 & B5 & B6 & & B1 & B2 & B3 & B4 & B5 & B6 \\
\hline A1 & 4.6 & 8.2 & 10.3 & 10.7 & 11.0 & 11.4 & A1 & 1.3 & 2.6 & 7.1 & 9.1 & 9.0 & 9.0 \\
\hline A2 & 3.0 & 6.7 & 9.1 & 9.6 & 9.9 & 10.3 & $\mathrm{~A} 2$ & 1.5 & 1.6 & 5.9 & 8.0 & 8.0 & 7.9 \\
\hline A3 & 2.1 & 5.2 & 7.9 & 8.5 & 8.8 & 9.1 & A3 & 3.8 & 1.9 & 3.4 & 5.6 & 5.8 & 5.8 \\
\hline $\mathrm{A} 4$ & 2.1 & 4.5 & 7.3 & 8.0 & 8.2 & 8.6 & A4 & 5.1 & 2.8 & 2.4 & 4.5 & 4.7 & 4.7 \\
\hline A5 & 2.0 & 4.4 & 7.2 & 7.9 & 8.1 & 8.5 & A5 & 5.3 & 3.1 & 2.2 & 4.3 & 4.5 & 4.6 \\
\hline \multirow[t]{2}{*}{ A6 } & 2.1 & 4.1 & 7.0 & 7.7 & 7.9 & 8.3 & A6 & 5.4 & 3.1 & 2.2 & 4.3 & 4.5 & 4.5 \\
\hline & C1 & C2 & C3 & $\mathrm{C} 4$ & C5 & C6 & & C1 & C2 & C3 & C4 & C5 & C6 \\
\hline B1 & 3.9 & 4.3 & 4.4 & 4.3 & 4.1 & 4.0 & B1 & 4.4 & 4.9 & 5.3 & 4.9 & 4.7 & 4.7 \\
\hline B2 & 2.2 & 2.9 & 3.3 & 3.3 & 3.2 & 3.1 & B2 & 3.3 & 3.9 & 4.6 & 4.3 & 4.2 & 4.2 \\
\hline B3 & 0.6 & 1.5 & 2.1 & 2.3 & 2.2 & 2.1 & B3 & 0.8 & 1.6 & 2.8 & 2.9 & 2.9 & 2.9 \\
\hline B4 & 0.4 & 1.0 & 1.7 & 1.9 & 1.8 & 1.8 & B4 & 0.9 & 0.5 & 1.8 & 2.1 & 2.1 & 2.1 \\
\hline B5 & 0.5 & 0.9 & 1.6 & 1.8 & 1.7 & 1.7 & B5 & 1.2 & 0.5 & 1.6 & 1.9 & 2.0 & 2.0 \\
\hline \multirow[t]{2}{*}{ B6 } & 0.6 & 0.7 & 1.5 & 1.6 & 1.6 & 1.6 & B6 & 1.2 & 0.5 & 1.5 & 1.9 & 1.9 & 1.9 \\
\hline & C1 & C2 & C3 & C4 & C5 & C6 & & C1 & $\mathrm{C} 2$ & C3 & C4 & C5 & C6 \\
\hline A1 & 5.4 & 5.5 & 5.3 & 5.1 & 5.0 & 4.9 & A1 & 4.6 & 5.1 & 5.4 & 5.0 & 4.8 & 4.8 \\
\hline $\mathrm{A} 2$ & 4.8 & 5.0 & 5.0 & 4.8 & 4.6 & 4.5 & $\mathrm{~A} 2$ & 3.9 & 4.5 & 5.0 & 4.6 & 4.5 & 4.5 \\
\hline A3 & 4.3 & 4.5 & 4.6 & 4.5 & 4.3 & 4.2 & A3 & 2.5 & 3.2 & 4.0 & 3.9 & 3.8 & 3.8 \\
\hline A4 & 4.0 & 4.3 & 4.4 & 4.3 & 4.2 & 4.1 & A4 & 1.9 & 2.6 & 3.6 & 3.5 & 3.5 & 3.5 \\
\hline A5 & 3.9 & 4.3 & 4.4 & 4.3 & 4.1 & 4.0 & A5 & 1.8 & 2.5 & 3.5 & 3.5 & 3.4 & 3.4 \\
\hline A6 & 3.8 & 4.2 & 4.3 & 4.2 & 4.1 & 4.0 & A6 & 1.8 & 2.5 & 3.5 & 3.5 & 3.4 & 3.4 \\
\hline \multicolumn{14}{|c|}{ A, B and C indicate the category of asphalt pavement } \\
\hline & Nun & rs $" 1$ & indi & WV & ands & & & $n: S$ & dis & & Red & rge & ance \\
\hline
\end{tabular}


COASTAL (BAND 1)

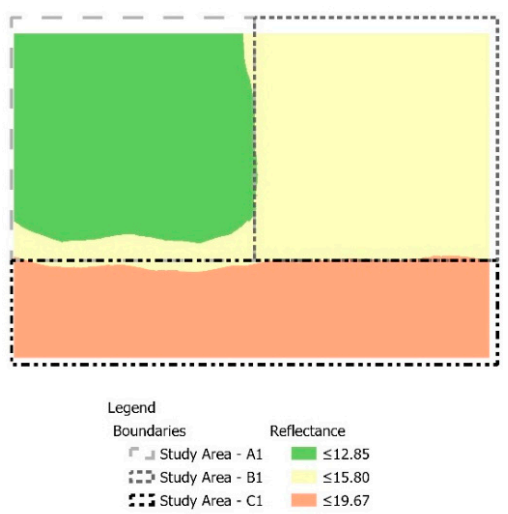

GREEN (BAND 3)

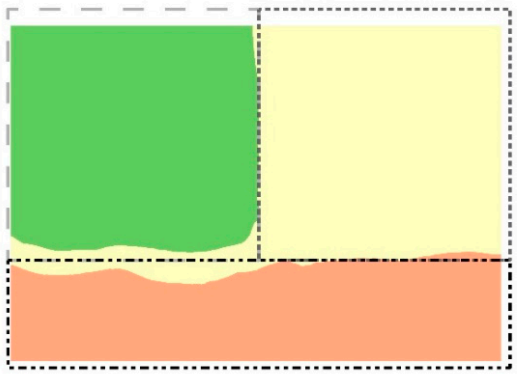

Legend

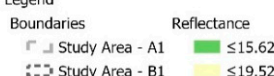

\begin{tabular}{lll} 
S Study Area - B1 & $\leq 19.52$ \\
\hdashline Study Area - C1 & $\leq 24.10$
\end{tabular}

RED (BAND 5)

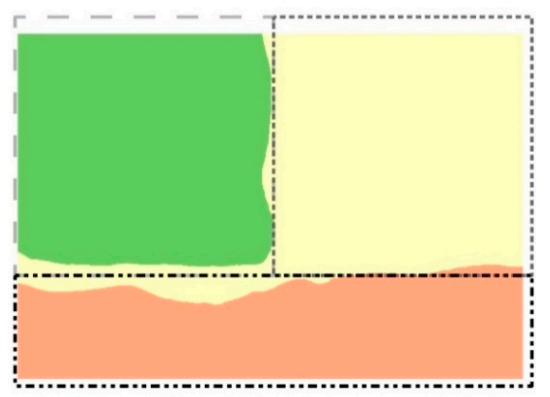

Legend

Boundaries Reflectanc

$r\lrcorner$ Study Area - A1 $=\leq 16.23$

$\begin{array}{rr}:-2 \text { Study Area - B1 } & \leq 20.29\end{array}$
BLUE (BAND 2)

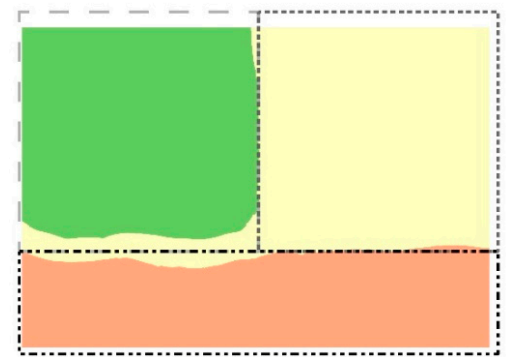

Legend

$\begin{array}{ll}\text { Boundaries } & \text { Reflectance } \\ r\lrcorner \text { Study Area - A1 } & \leq 14.23\end{array}$

$\begin{array}{ll}\lrcorner \text { Study Area - A1 } & \leq 14.23 \\ \text { Study Area - B1 } & \leq 17.65\end{array}$

Study Area - C1

YELLOW (BAND 4)

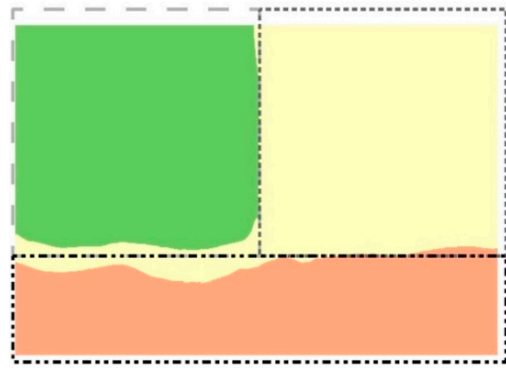

Legend

Boundaries Reflectance

Study Area - A1 $\leq 16.20$

$\because$ Study Area - B1 $\quad \leq 20.21$

RED-EDGE (BAND 6)

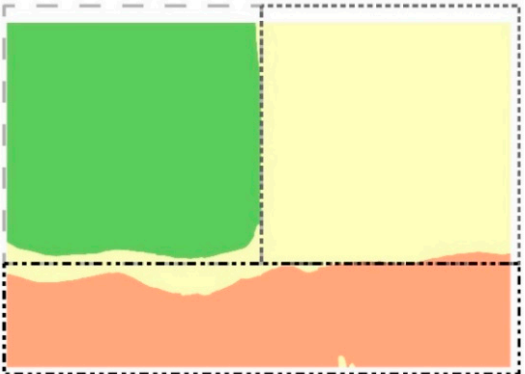

Legend

Boundaries Reflectance

$\begin{aligned} \triangle \text { Study Area - A1 } & \leq 16.52 \\ \text { Study Area - B1 } & \leq 20.51\end{aligned}$

$\because:$ Study Area - C1 $\quad \leq 25.33$

Figure 10. Classification of the three asphalt pavement age categories by using the reflectance values in each WV3 band examined.

By using bands 6 and 1 as the best bands to characterize (separate) the age of asphalt pavements, Figure 11 was created. The classification of the three asphalt pavement categories is obvious. The blue color represents Age category 1, the orange color is Age category 2 and the grey color is Age category 3. It is evident that there is a separation between the three categories using the combination of the suggested bands. Age category 1 refers to the asphalt class A, Age category 2 refers to the asphalt class $\mathrm{B}$, and Age category 3 refers to the asphalt class $\mathrm{C}$. 


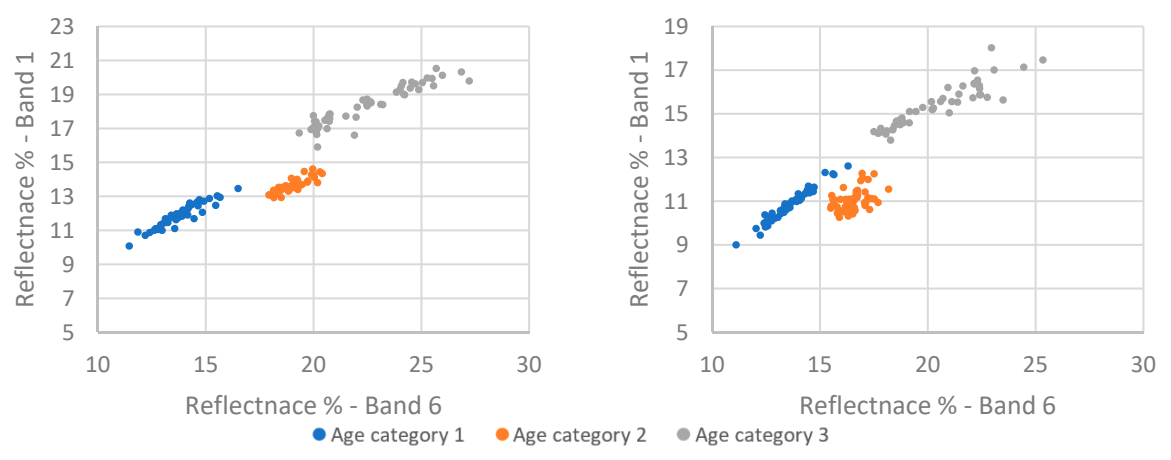

Figure 11. Band 1/Band 6 graphs for spectroradiometer (left) and colorimeter (right).

The next step of the application is to vectorize the two asphalt pavements (out of three) using a range of reflectance for each asphalt pavement category for a WV3 spectral band. For example, for band 1 , the reflectance ranging to $12.85 \%$ belongs in category $\mathrm{A}$, while the reflectance ranging from $12.86-15.79 \%$ belongs in category $\mathrm{B}$. Then, a vectorization of the asphalts takes place, and a normalization equation can be used to compare the two asphalt pavement age categories at once. In this way, there will be noise reduction from the surrounding environment. Thereafter, more age categories may enter the GIS environment.

The Normalized Difference Equation/filter for asphalt Pavement Age characterization Index (NDPAI) used is:

$$
\frac{\text { Band }_{6}-\text { Band }_{1}}{\text { Band }_{6}+\text { Band }_{1}}
$$

where band refers to WV3 bands ( 6 is the red-edge and 1 is the coastal band).

The results in using the normalization equation/filter can be seen in Figure 12. The left side of the figure (Figure 12a) shows the application of the NDPAI. There is a clear separation of Asphalt Pavement Category A and B. Although, Category C is separate from the other two categories, its values are closer to the ones of Category A. This can be explained using the chart of Figure 12b where there is a clear difference between the Category A and B while the values of Category $C$ are in between $A$ and $\mathrm{B}$ and closer to $\mathrm{A}$. This is the reason for applying the NDPAI mentioned above on two categories each at once instead of more than two. By applying NDPAI, the asphalt pavements are isolated. In other words, only the area of interest will be examined by minimizing surrounding noise.

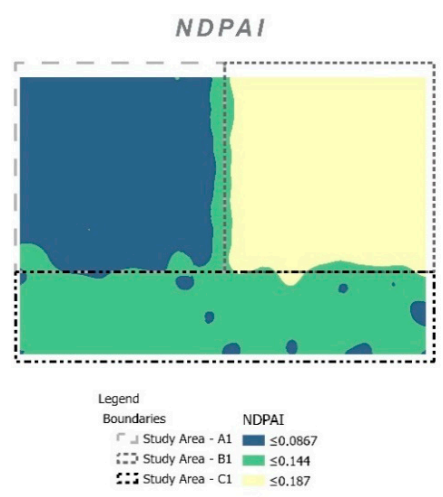

(a)

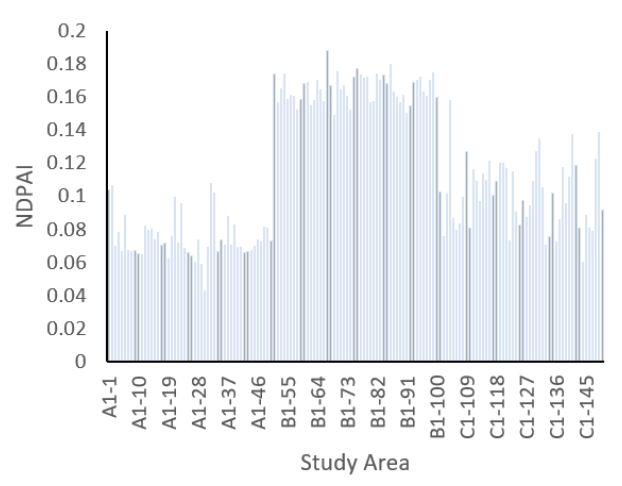

(b)

Figure 12. Use of the normalized filter (NDPAI) on the three asphalt pavement categories (a) and application of B6 - B1/B6 + B1 to the three pavement regions studied (b).

\section{Conclusions}

While the color science has a wide range of applications, limited work has been performed on the color of asphalt pavements in the CIE $\mathrm{L}^{*} \mathrm{a}^{*} \mathrm{~b}^{*}$ color space. Asphalt pavements have been widely 
studied using spectral signatures and satellite data. Besides the fact that asphalt pavements were not studied thoroughly in terms of color, the equipment used to study asphalt pavements are considered to be specialized equipment; thus, they are also expensive.

The main aim of the paper was to use colorimeter data to study parameters of asphalt pavements, such as their age. This is usually performed using spectroradiometers, so the methodology was accomplished through the comparison of colorimeter data to spectroradiometer data. This comparison was done by converting all data to color space $\mathrm{L}^{*} \mathrm{a}^{*} \mathrm{~b}^{*}$ and also by applying the vice versa conversion, i.e., by converting the data to spectral data. In this way, researchers can have a handy tool to work with the characteristics of asphalt pavements using both spectral and color data.

The results showed that there is a downgrading of parameter $\mathrm{L}^{*}$ (lightness) by using the colorimeter data, but in general, all the data are in line with literature since it shows that the $L^{*}$ for both equipment (spectroradiometer and colorimeter) increases as the age of the asphalt pavement increases as well. In addition, statistics were used to confirm that age categories of asphalt pavements cannot be mismatched using both pieces of equipment. Statistically, the colorimeter data proved to comply with the spectroradiometer data.

When spectral data were compared for both equipment using six multispectral bands of WV3 satellite, the outcomes showed consistency for the two equipment used. The separability indices (Euclidean, Mahalanobis distances) were in line for both equipment for the age categorization of asphalt pavements. The combination of Band 6 (Red-edge) and Band 1 (Coastal), as far as WV3 concerns, proved to be the most appropriate separability index for age characterization of asphalt pavements for colorimeter and spectroradiometer data.

As a synopsis, a colorimeter can be used for the calibration of satellite data since its data are in line with spectroradiometric data. By using all information, an application of a proposed Normalized Difference Equation/filter for asphalt Pavement Age characterization Index (NDPAI) was performed, showing how asphalt pavements can be categorized through their age category.

It is worth mentioning that the methodology described in the study makes some important assumptions about the six study areas. The only variable for the study areas was their age of construction, while other parameters, such as traffic load, construction manuals, weather conditions etc. were considered to be the same for each area of study. It should be noted that the application of the results using WV3 specifications is a first step in the upscaling of colorimeter data to satellite data, since it took place in a small region without any satellite image. Future work may be focused on using the conclusions of this work on a satellite image to study paved conditions.

Author Contributions: Conceptualization, C.M.; Methodology, C.M., E.E. and A.A.; Formal analysis, C.M. and E.E.; Software, C.M. and E.E.; Investigation, C.M. and E.E.; Resources, C.M.; Writing-original draft preparation, C.M.; Writing-review and editing, C.M., E.E., A.A. and D.H.; Visualization, C.M.; Project administration, C.M.; Supervision, D.H. All authors have read and agreed to the published version of the manuscript.

Funding: This research received no external funding.

Acknowledgments: The authors would like to acknowledge the "CUT Open Access Author Fund" for covering the open access publication fees of the paper. The authors acknowledge the support of the 'ERATOSTHENES: Excellence Research Centre for Earth Surveillance and Space-Based Monitoring of the Environment-'EXCELSIOR' project (https://excelsior2020.eu/) that has received funding from the European Union's Horizon 2020 research and innovation programme under grant agreement No 857510 (Call: WIDESPREAD-01-2018-2019 Teaming Phase 2) and the Government of the Republic of Cyprus through the Directorate General for European Programmes, Coordination and Development. This paper refers to the work of the Ph.D. activities of the corresponding author, Christodoulos Mettas, at the Cyprus University of Technology, Department of Civil Engineering and Geomatics, which is under the auspices of the activities of the 'EXCELSIOR' H2020 Widespread Teaming Phase 2 project. The authors would like to express their appreciation to the Public Works Department (Ministry of Transport, Communications and Works, Republic of Cyprus) in Paphos and Larnaca District areas and the District Administration Office in Pafos (Ministry of Interior, Republic of Cyprus) for their support during the field campaigns as well for the provision of data regarding the asphalt pavements.

Conflicts of Interest: The authors declare no conflict of interest. 


\section{References}

1. Mei, A.; Fiore, N.; Salvatori, R.; D'Andrea, A.; Fontana, M. Spectroradiometric Laboratory Measures on Asphalt Concrete: Preliminary Results. Procedia Soc. Behav. Sci. 2012, 53, 514-523. [CrossRef]

2. Manzo, C.; Mei, A.; Salvatori, R.; Bassani, C.; Allegrini, A. Spectral Modelling Used to Identify the Aggregates Index of Asphalted Surfaces and Sensitivity Analysis. Constr. Build. Mater. 2014, 61, 147-155. [CrossRef]

3. Carmon, N.; Ben-Dor, E. Mapping Asphaltic Roads' Skid Resistance Using Imaging Spectroscopy. Remote Sens. 2018, 10, 430. [CrossRef]

4. Liu, K.; Su, H.; Zhang, L.; Yang, H.; Zhang, R.; Li, X. Analysis of the Urban Heat Island Effect in Shijiazhuang, China Using Satellite and Airborne Data. Remote Sens. 2015, 7, 4804-4833. [CrossRef]

5. Mei, A.; Salvatori, R.; Fiore, N.; Allegrini, A.; D'Andrea, A. Integration of Field and Laboratory Spectral Data with Multi-Resolution Remote Sensed Imagery for Asphalt Surface Differentiation. Remote Sens. 2014, 6, 2765-2781. [CrossRef]

6. Mettas, C.; Agapiou, A.; Themistocleous, K.; Neocleous, K.; Hadjimitsis, D.; Michaelides, S. Risk Provision Using Field Spectroscopy to Identify Spectral Regions for the Detection of Defects in Flexible Pavements. Nat. Hazards 2016, 83, 1-14. [CrossRef]

7. Mettas, C.; Themistocleous, K.; Neocleous, K.; Christofe, A.; Pilakoutas, K.; Hadjimitsis, D.; Engineering, S. Monitoring Asphalt Pavement Damages Using Remote Sensing Techniques. In Proceedings of the SPIE 9535, Third International Conference on Remote Sensing and Geoinformation of the Environment (RSCy2015), Paphos, Cyprus, 16-19 March 2015.

8. Rodés, J.P.; Reguero, A.M.; Pérez-Gracia, V. GPR Spectra for Monitoring Asphalt Pavements. Remote Sens. 2020, 12, 1749. [CrossRef]

9. Alakian, A.; Achard, V. Classification of Hyperspectral Reflectance Images with Physical and Statistical Criteria. Remote Sens. 2020, 12, 2335. [CrossRef]

10. Yuan, Y.; Jalón-Rojas, I.; Wang, X.H. Impact of Coastal Infrastructure on Ocean Colour Remote Sensing: A Case Study in Jiaozhou Bay, China. Remote Sens. 2019, 11, 946. [CrossRef]

11. Agapiou, A. Vegetation Extraction Using Visible-Bands from Openly Licensed Unmanned Aerial Vehicle Imagery. Drones 2020, 4, 27. [CrossRef]

12. Oleari, C. Standard Colorimetry: Definitions, Algorithms and Software; Wiley: Hoboken, NJ, USA, 2016.

13. Roy, S.B. Billmeyer and Saltzman's Principles of Color Technology; Wiley: Hoboken, NJ, USA, 2019.

14. Lee, H.; Kim, Y. Laboratory Evaluation of Color Polymer Concrete Pavement with Synthetic Resin Binder for Exclusive Bus Lanes. Transp. Res. Rec. 2007, 1991, 124-132. [CrossRef]

15. DiGioia, J.; Watkins, K.E.; Xu, Y.; Rodgers, M.; Guensler, R. Safety Impacts of Bicycle Infrastructure: A Critical Review. J. Safety Res. 2017, 61, 105-119. [CrossRef] [PubMed]

16. Ando, R.; Inagaki, T.; Mimura, Y. Does Colored Pavement Make Non-Signalized Intersections Safer? Case Study in Japan. Procedia Soc. Behav. Sci. 2011, 20, 741-751. [CrossRef]

17. Pascual-Muñoz, P.; Castro-Fresno, D.; Serrano-Bravo, P.; Alonso-Estébanez, A. Thermal and Hydraulic Analysis of Multilayered Asphalt Pavements as Active Solar Collectors. Appl. Energy 2013, 111, 324-332. [CrossRef]

18. Diefenderfer, B.K.; Al-Qadi, I.L.; Diefenderfer, S.D. Model to Predict Pavement Temperature Profile: Development and Validation. J. Transp. Eng. 2006, 132, 162-167. [CrossRef]

19. Akbari, H.; Konopacki, S. Calculating Energy-Saving Potentials of Heat-Island Reduction Strategies. Energy Policy 2005, 33, 721-756. [CrossRef]

20. Akbari, H.; Menon, S.; Rosenfeld, A. Global Cooling: Increasing World-Wide Urban Albedos to Offset $\mathrm{CO}_{2}$. Clim. Chang. 2009, 94, 275-286. [CrossRef]

21. Herold, M.; Roberts, D. Spectral Characteristics of Asphalt Road Aging and Deterioration: Implications for Remote-Sensing Applications. Appl. Opt. 2005, 44, 4327-4334. [CrossRef]

22. Noronha, V.; Herold, M.; Roberts, D.; Gardner, M. Spectrometry and Hyperspectral Remote Sensing for Road Centerline Extraction and Evaluation of Pavement Condition. In Proceedings of the Pecora Conference; National Consortium on Remote Sensing in Transportation-Infrastructure Management: Denver, CO, USA, 2002; p. 12.

23. Autelitano, F.; Giuliani, F. Daytime and Nighttime Color Appearance of Pigmented Asphalt Surface Treatments. Constr. Build. Mater. 2019, 207, 98-107. [CrossRef]

24. Lin, D.F.; Luo, H.L. Fading and Color Changes in Colored Asphalt Quantified by the Image Analysis Method. Constr. Build. Mater. 2004, 18, 255-261. [CrossRef] 
25. Ning, S.; Huan, S. Experimental Study on Color Durability of Color Asphalt Pavement. IOP Conf. Ser. Mater. Sci. Eng. 2017, 207, 012104. [CrossRef]

26. Pascual-Muñoz, P.; Castro-Fresno, D.; Carpio, J.; Zamora-Barraza, D. Influence of Early Colour Degradation of Asphalt Pavements on Their Thermal Behaviour. Constr. Build. Mater. 2014, 65, 432-439. [CrossRef]

27. Hunt, R.W.G.; Pointer, M.R. Measuring Colour, 4th ed.; Wiley: Hoboken, NJ, USA, 2011.

28. FRU. FRU-WR 18. Available online: http://www.colorinstrument.cn/index.php/product/index/id/47.html (accessed on 27 July 2020).

29. Lindbloom, B. Useful Colour Equations. 2013. Available online: http://www.brucelindbloom.com/index. html?Math.html (accessed on 1 April 2020).

30. CIE. CIE Technical Report: Colorimetry, 3rd ed.; CIE: Vienna, Austria, 2004.

31. Schanda, J. CIE Colorimetry. In Colorimetry: Understanding the CIE System; Wiley: Hoboken, NJ, USA, 2007. [CrossRef]

32. CIE. Colorimetry; CIE Progress Report of CIE Technical Committee: London, UK, 1975; pp. 161-172.

33. Burns, S.A. Numerical Methods for Smoothest Reflectance Reconstruction. Color Res. Appl. 2020, 45, 8-21. [CrossRef]

34. Burns, S.A. Generating Reflectance Curves from SRGB Triplets. arXiv 2020, arXiv:1710.05732. Available online: https://arxiv.org/abs/1710.05732 (accessed on 1 April 2020).

35. Wyszecki, G.S.W. Color Science, Concepts and Methods, Quantitative Data and Formulae, 2nd ed.; Wiley and Sons: New York, NY, USA, 1982.

36. Hadjimitsis, D.G.; Clayton, C. Field Spectroscopy for Assisting Water Quality Monitoring and Assessment in Water Treatment Reservoirs Using Atmospheric Corrected Satellite Remotely Sensed Imagery. Remote Sens. 2011, 3, 362-377. [CrossRef]

37. Agapiou, A.; Alexakis, D.D.; Sarris, A.; Hadjimitsis, D.G. Orthogonal Equations of Multi-Spectral Satellite Imagery for the Identification of Un-Excavated Archaeological Sites. Remote Sens. 2013, 5, 6560-6586. [CrossRef]

38. Kuester, M. Radiometric Use of WorldView-3 Imagery; DigitalGlobe: Longmont, CO, USA, 2016.

39. Abdalla, A.; Cen, H.; Abdel-Rahman, E.; Wan, L.; He, Y. Color Calibration of Proximal Sensing RGB Images of Oilseed Rape Canopy via Deep Learning Combined with K-Means Algorithm. Remote Sens. 2019, 11, 3001. [CrossRef]

40. Csillik, O.; Belgiu, M.; Asner, G.P.; Kelly, M. Object-Based Time-Constrained Dynamic Time Warping Classification of Crops Using Sentinel-2. Remote Sens. 2019, 11, 1257. [CrossRef]

41. Li, Q.; Zheng, B.; Tu, B.; Yang, Y.; Wang, Z.; Jiang, W.; Yao, K.; Yang, J. Refining Urban Built-up Area via Multi-Source Data Fusion for the Analysis of Dongting Lake Eco-Economic Zone Spatiotemporal Expansion. Remote Sens. 2020, 12, 1797. [CrossRef]

42. Ma, W.; Li, P. An Object Similarity-Based Thresholding Method for Urban Area Mapping from Visible Infrared Imaging Radiometer Suite Day/Night Band (VIIRS DNB) Data. Remote Sens. 2018, 10, 263. [CrossRef]

43. Mahalanobis, P.C. On the Generalized Distance in Statistics. In National Institute of Sciences of India: Odisha, India; NISER: Odisha, India, 1936; Volume 2, pp. 49-55.

44. Siomos, N.; Fountoulakis, I.; Natsis, A.; Drosoglou, T.; Bais, A. Automated Aerosol Classification from Spectral UV Measurements Using Machine Learning Clustering. Remote Sens. 2020, 12, 965. [CrossRef]

45. Xiang, S.; Nie, F.; Zhang, C. Learning a Mahalanobis Distance Metric for Data Clustering and Classification. Pattern Recognit. 2008, 41, 3600-3612. [CrossRef]

46. Kubiak-Wójcicka, K. Variability of Air Temperature, Precipitation and Outflows in the Vistula Basin (Poland). Resources 2020, 9, 103. [CrossRef]

47. Lee, S.; Jang, J.; Kim, Y.; Cho, N.; Lee, M. Susceptibility Analysis of the Mt. Umyeon Landslide Area Using a Physical Slope Model and Probabilistic Method. Remote Sens. 2020, 12, 2663. [CrossRef]

Publisher's Note: MDPI stays neutral with regard to jurisdictional claims in published maps and institutional affiliations. 